\title{
LAS PERIODISTAS JUARENSES: DE SU IRRUPCIÓN EN LA INFORMACIÓN GENERAL Y SU ARRIBO A LOS ESPACIOS DE DECISIÓN. EL GÉNERO EN EL MUNDO DEL TRABAJO MEDIÁTICO ${ }^{1}$
}

Resumen: ¿Cómo fue que cinco mujeres arribaron a las direcciones editoriales y generales de tres diarios en Ciudad Juárez, Chihuahua? Esta investigación se enfoca a la incursión femenina en el periodismo de información general y de opinión, campo antes vedado para mujeres. Ellas enfrentaron barreras de género -techos de cristal-, e idearon tácticas para resistir. Se reflexiona si el mando femenino ha transgredido o no las representaciones de las mujeres en los medios, éstos, como estructuras del patriarcado, reafirman estereotipos de género y nos infravaloran. La metodología consistió en entrevistas a profundidad y semiestructuradas, grupos focales y análisis de contenido.

Palabras clave: género, mujeres, muros y techos de cristal, patriarcado, periodistas

Abstract. How did five women get to the editorial and general addresses of three newspapers in Ciudad Juarez, Chihuahua? This research focuses on the female incursion into general information and opinion journalism, a previously closed field for women. They faced gender barriers -glass ceilings-, and devised tactics to resist. The female leadership has not transgressed the representations of women in the media, these as structures of patriarchy, reaffirm gender stereotypes and undervalue us. The methodology consisted of in-depth and semi-structured interviews, focus groups and content analysis.

Keywords. gender, women, walls and glass ceilings, patriarchy, journalists

\footnotetext{
${ }^{1}$ Artículo de avances del proyecto de investigación Mujeres y frontera: Las periodistas en Ciudad Juárez. De sus batallas por la primera plana y su arribo a las direcciones, que se realizó con recursos del Programa de Mejoramiento del Profesorado Prodep.

${ }^{2}$ Profesora-investigadora adscrita al departamento de Ciencias Sociales de la Universidad Autónoma de Ciudad Juárez; experiodista de medios impresos; doctora en Investigación por El Colegio de Chihuahua; miembro del Cuerpo Académico 76 de la UACJ, Estudios de las Mujeres, Región y Fronteras; lcastill@uacj.mx.
} 


\section{Introducción}

En el marco de la creciente incorporación de las mujeres al mundo del trabajo asalariado, en un contexto nacional de cambios políticos, incluido el paso del periodismo subordinado a un modelo de mayor autonomía económica, con mayores márgenes de libertad y de carácter más crítico; ${ }^{3}$ en el estado mexicano de Chihuahua, en la década de 1980 las periodistas irrumpieron en los espacios de la información general y de opinión, ${ }^{4}$ áreas otrora consideradas no femeninas (Castillo, 2011), de manera que, a finales del siglo XX en esta entidad la participación de las mujeres en el campo del periodismo se había normalizado en el área reporteril.

En la misma época algunas de ellas incursionaron en puestos de mando, coordinaciones de unidades de investigación, jefaturas de información y, en dos medios en la dirección editorial. ${ }^{5}$ En el caso de Ciudad Juárez, Chih., el ascenso de ellas continuó en el nuevo siglo: entre 2010 y 2015, tres periodistas, una empresaria y una administradora arribaron a las direcciones editoriales y generales de tres diarios locales.

A contracorriente de la tendencia nacional e incluso internacional, la cual se orienta a que las mujeres en los medios siguen siendo minoría y en pocos casos llegan a los puestos de decisión. Estas diferencias en el ascenso de ellas en diferentes cargos en las redacciones de los medios han sido tema de estudio de los medios conocidos como nacionales (los ubicados en la capital del país), así, en 2011 se reportaba que, en México, únicamente dos mujeres eran directoras de periódicos: Carmen Lira, en La Jornada, y Pilar Estandía en El Financiero (Fernández, 2011).

\footnotetext{
${ }^{3}$ Como lo analiza Hernández (2010), desde su origen el periodismo mexicano moderno operó bajo un modelo económico-proteccionista, que Carreño (2000) describe como estructural. El sistema, que corresponde al carácter corporativista típico del sistema político unipartidista de este país, habría entrado en crisis en la primera mitad de la década de los años 1980.

${ }^{4}$ Por periodismo de información general en este documento se referirá a la recolección, edición y difusión de información en áreas distintas a las consideradas de entretenimiento como deportes, sociales y espectáculos, mientras que al hablar de los espacios de opinión se entiende aquellos artículos de opinión y columnas editoriales y políticas.

${ }^{5}$ La Organización Editorial Mexicana (OEM) designó en 1985 a la primera directora de un periódico en el estado de Chihuahua, Isabel Gutiérrez Estrada en El Sol de Parral, cargo que ocupó hasta 2005. En junio de 1991 en el diario El Fronterizo, también propiedad de dicha compañía, fue nombrada directora Leticia Landavazo Carrillo, quien permaneció hasta la fecha de cierre de ese medio (junio de 1995), luego ella dirigió por tres años el vespertino El Mexicano, impreso de la misma empresa que se publica en Ciudad Juárez.
} 
La presencia de mujeres en las direcciones de periódicos juarenses deriva en una serie de procesos sociales que no se habían documentado. La primera de esas implicaciones refiere al orden de las subjetividades, en torno a la valiosa experiencia particular de cada una de estas mujeres y toda la carga que se observa en su trayectoria en diversos espacios, y en concreto en el ámbito laboral, en el que conquistan puestos que antes ocuparon únicamente hombres.

La segunda cuestión es más del espectro social, se deriva de la anterior y tiene un impacto más amplio en cuanto al imaginario social que puede llegar a afectar, se refiere a las audiencias y el tratamiento de la noticia, es decir, las repercusiones que pudieran tener las decisiones de mujeres en el contenido de las publicaciones de esos medios, sobre todo cuando los mensajes son acerca del sexo femenino.

Un referente obligado para acercarse a este tema es el Proyecto de Monitoreo Global de Medios (GMMP, por sus siglas en inglés), monitoreo simultáneo de medios en diversos países que desde 1995 se realiza cada cinco años, para registrar indicadores de presencia y representaciones de las mujeres en los medios, en relación con los hombres.

Los resultados de estos monitoreos muestran como tendencia general que las mujeres constituyen una minoría en los medios y muy pocas ocupan puestos de decisión, al tiempo que los estereotipos acerca de nosotras en los contenidos son recurrentes; además, que estamos subrepresentadas como fuentes de información y como protagonistas de las noticias. (Vega, 2012).

La última observación del GMMP se realizó el 25 de marzo de 2015, ese día en México se analizaron 554 noticias en 33 medios de comunicación; se encontró que cuando las mujeres se incluyeron en las noticias analizadas, un 60 por ciento de ellas fueron entrevistadas como parte de la opinión popular (vox populli), un 28 por ciento como expertas o comentaristas, un 19 por ciento como voceras, y sólo el uno por ciento fue abordada para exponer su experiencia en algún tema.

En contraste, en la misma muestra de noticias, el 92 por ciento de los hombres fueron entrevistados como expertos o comentaristas. (GMMP et al., 2015). Con tal desequilibrio, simbólicamente los contenidos de los medios comunican que quienes saben son ellos, que los hombres tienen conocimientos más calificados que las mujeres. 
Es en este contexto que se propuso documentar e interpretar los procesos que han vivido las mujeres periodistas en Ciudad Juárez, buscando generar conocimiento de las particularidades del periodismo juarense y la impronta femenina en un ámbito laboral que tiene la peculiaridad de ser una importante arena de lo público. El estudio aspira aportar conocimiento al campo de los estudios sociales de comunicación y de género desde una experiencia de orden local, desde una urbe fronteriza afamada recientemente por hechos violentos que también han trastocado el ejercicio periodístico.

El proyecto parte de dos premisas o supuestos, a manera de ideas orientadoras (Blumer, 1954); el primer punto es que por razones de género las mujeres han enfrentado diversos obstáculos en su carrera como periodistas, dificultades que se sostienen o pueden acentuarse cuando ocupan puestos de mando; la segunda cuestión es que la participación de mujeres como directivas de medios no ha derivado en un periodismo no sexista, entendido éste como "un trabajo profesional con perspectiva de género que visibilice, desde un lenguaje sin estereotipos, la condición social en que viven las mujeres" (CIMAC, 2011, p.8), es decir, un periodismo que no subrepresente, desvalorice ni estereotipe a las personas según su sexo.

En este estudio se concibe a las mujeres como sujetas históricas sociales. Con un enfoque de género se aborda su presencia y las relaciones de género en el periodismo; entre otras cuestiones se revisa cuáles roles se les asignan a ellas y a ellos, y cómo desde sus subjetividades se plantean lo femenino y lo masculino.

Se utilizan las metáforas de Techos y Laberintos de Cristal (Burin, 1996 y 2011), formuladas para evidenciar las barreras "invisibles" (no escritas, pero establecidas culturalmente) que enfrentamos las mujeres al escalar a puestos jerárquicos, principalmente en el ámbito laboral y político (Rosado, 2016).

Las preguntas que condujeron esta investigación son: 1) ¿Cómo se posicionaron las mujeres periodistas de Ciudad Juárez, Chihuahua, en el área de información general? 2) ¿Cómo fueron las trayectorias de las directoras de periódicos? 3) ¿Se dio un trato diferente a las mujeres en los contenidos de los medios dirigidos por mujeres?

De éstas se deriva el objetivo general de investigación: documentar y analizar cómo ha sido la inserción de las mujeres periodistas en las áreas de información general de los medios de comunicación de Ciudad Juárez, Chihuahua, incluida la trayectoria de las 
directoras de periódicos impresos. Asimismo, evaluar si su presencia en puestos de decisión repercute o no, en un trato diferente de los medios hacia las mujeres como protagonistas o tema de las noticias.

El proyecto abarcó tres ejes:

$1^{\text {o }}$. El componente histórico, consistente en documentar la irrupción de las mujeres periodistas en los espacios considerados no apropiados para ellas. Buscando información detallada de quiénes, cuándo, en cuáles medios y en cuáles áreas de trabajo iniciaron

$2^{\circ}$. La aproximación a las subjetividades e intersubjetividades de las periodistas, una estrategia encaminada a conocer cómo fueron los procesos de estas mujeres, cómo reconstruyen y significan su experiencia, qué vivieron como mujeres en el periodismo.

$3^{\circ}$. Análisis de contenido en publicaciones del antes y después de medios dirigidos por mujeres. Se realizó este trabajo con el propósito de explorar las consecuencias del mando femenino en el trato mediático hacia las mujeres y los asuntos de género.

Este documento contiene los avances de la investigación, la cual está en la fase final del análisis de contenido. Después de la introducción se resume la estrategia metodológica; en un tercer apartado se desglosan los hallazgos distribuidos en los tres ejes que abarca el proyecto. Finalmente, se presentan conclusiones preliminares.

\section{Notas de la estrategia metodológica}

Esta investigación se inscribe en el paradigma interpretativo como una forma específica de pensar y abordar la realidad social (Denzin \& Lincoln, 2011, 1985; Strauss y Corbin, 2002).

Es una aproximación con perspectiva de género que identifica el sistema social como patriarcal cuyas estructuras se han cimentado bajo la lógica androcentrista, lo cual es más evidente u observable en los campos de la esfera pública, como el mundo del trabajo (Barberá, Ramos y Candela, 2011).

Se optó por una estrategia metodológica de carácter cualitativo porque se planteó conocer la textura los procesos de las principales participantes en la investigación (las mujeres periodistas en Ciudad Juárez), sus subjetividades e intersubjetividades, en su relación con los momentos que vivieron como mujeres en el periodismo. 
Además, se utilizó una técnica que contiene aspectos cuantitativos y cualitativos, el análisis de contenido, con el cual se puede evaluar la participación de mujeres periodistas en los distintos espacios de los tres diarios, así como las noticias y artículos que mencionan a mujeres y cómo las mencionan.

El trabajo empírico consistió en 22 entrevistas individuales (ocho a profundidad y 14 semiestructuradas, 17 a mujeres y tres a hombres), una entrevista grupal y dos grupos focales, ${ }^{6}$ así como el análisis de contenido aplicado a una muestra de publicaciones en dos medios dirigidos por mujeres.

La selección de las participantes en este proyecto se derivó fundamentalmente de cuestiones relativas a las preguntas y objetivos del proyecto, pero también de la accesibilidad a ellas; se buscó conocer las experiencias de mujeres de distintas generaciones que participaron o participan en el periodismo de información general y político en Ciudad Juárez, así como de las que llegaron a ocupar puestos de mando en los medios. ${ }^{7}$

En ciertos momentos el abordaje tuvo un carácter autorreferencial, pues la autora fue periodista entre 1980 y 1999, en la etapa de la irrupción de las mujeres en las áreas de información general y política; la intersubjetidad de entrevistadas y entrevistadora fue más intensa al conversar entre excolegas de ese tiempo.

Para el análisis de las conversaciones entabladas en las entrevistas y los grupos focales, se aplicó la técnica de codificación abierta propuesta por especialistas en la estrategia de teoría fundamentada o grounded theory (Strauss y Corbin, 2002), un microanálisis de texto, que consiste en etiquetar o dar un código a determinados segmentos de la narrativa o conversación, según sea el caso; al decidir cómo nombrar las enunciaciones que surgen en las aproximaciones cualitativas comienza la acción interpretativa, es así, la fase inicial del análisis, y puede ser una interpretación tentativa que se revisará de acuerdo a su relación contextual y con el conjunto del resto de la información obtenida.

\footnotetext{
${ }^{6}$ En un grupo focal participaron mujeres periodistas o experiodistas, y en el otro únicamente hombres. En el primero se buscó recuperar las experiencias de las protagonistas de este estudio, en el segundo explorar la memoria y las visiones de ellos sobre sus compañeras.

${ }^{7}$ La única exdirectora editorial que no fue posible entrevistar fue Miroslava Breach Velducea (asesinada el 23 de marzo de 2017), a quien tratamos de contactar cuando ya no radicaba en esta ciudad.
} 
En lo que concierne al análisis de contenido, esta técnica se utilizó para explorar la participación femenina en los medios -antes y después de las directoras-, así como el tratamiento mediático del que son objeto las mujeres, lo que respondería a la tercera pregunta de investigación [¿se dio un trato diferente a las mujeres en los contenidos de los medios dirigidos por mujeres?].

Este análisis de contenido se aplicó a una muestra de 13 ejemplares de periódicos compuesta por seis de El Diario de Juárez y siete de Norte de Ciudad Juárez.

El criterio de la selección consistió en que fuesen publicaciones de distintos años para abarcar el antes y después de ser dirigidos por mujeres. Se trata de una muestra intencional con un criterio de representatividad no cuantitativo, que observa y analiza los contenidos de determinados ejemplares, considerando que éstos son arquetipos de las publicaciones de los medios locales en cuestión.

En el aspecto de la participación femenina en los medios, se comparó cuántos y cuáles contenidos fueron escritos por mujeres y cuántos por hombres, esta comparación se focalizó por secciones.

Para abordar las representaciones que se hacen de las mujeres se seleccionaron los contenidos en los que ellas son mencionadas, se realizó una primera codificación para indicar si en los mensajes fueron tema, protagonistas, fuentes de la información o voces de opinión (vox populli), y una segunda, para ahondar de qué manera se les representa (como víctimas, culpables, empoderadas, expertas, etcétera).

Esta es la parte del análisis de información que está en curso, abarca mil 530 contenidos, 799 de El Diario de Juárez y 731 de Norte de Ciudad Juárez.

\section{Descripción de hallazgos. Cuatro momentos de un proceso sociohistórico}

En México, la llegada de las mujeres en el periodismo de información general y política se inscribe en una escena nacional de cambios políticos y culturales que datan de 1960 y tienen auge en el 2000, con la alternancia en la presidencia de la república (García, 2012 y Valles, 2006). 
En el caso de Ciudad Juárez, Chih., se pueden identificar cuatro momentos de la participación femenina en esas áreas del periodismo: el momento de las pioneras o iniciadoras, su irrupción en 1980, una impronta femenina observada en los 1990, y, la era de las directoras.

1) La época de las pioneras. A lo largo de las décadas de 1960 y 1970, las mujeres comienzan a desafiar los cánones de su tiempo y salen al mundo de trabajo ${ }^{8}$.

En los medios de información no todas aceptan tareas representadas como femeninas, en las que suelen ser auxiliares de varones (secretarias, recepcionistas, contadoras, mecanógrafas, etcétera).

Aunque algunas inician como cronistas de sociales ${ }^{9}$ o recepcionistas, llegaron a ser secretarias de redacción, reporteras de información general y de secciones especiales. ${ }^{10}$

2) El momento de la irrupción. La incursión de más mujeres en el periodismo de información general y político es un proceso que destaca en el segundo lustro de la década de 1980 .

Coincide con el tiempo de la "profesionalización"ll del periodismo, de forma numerosa a los medios arriban practicantes, egresados y egresadas de escuelas de comunicación y de periodismo. ${ }^{12}$

\footnotetext{
${ }^{8}$ Es el tiempo de la llamada Segunda ola del movimiento de liberación de la mujer en Estados Unidos, período en el que se ubica también el Año Internacional de la Mujer por parte de la ONU (1975) y la primera conmemoración del Día Internacional de la Mujer.

${ }^{9}$ Las secciones de Sociales, también tituladas de otras formas como Gente, son aquellas dedicadas a difundir eventos sociales y culturales, abundan información de actos festivos de personalidades de la sociedad como bodas, aniversarios, graduaciones, reuniones de clubes sociales, inauguraciones, etcétera.

${ }^{10}$ Un caso ilustrativo es el de Adela Sierra de González, que a sus 14 años inicia como recepcionista en una estación de radio, luego, su empleo de secretaria del director de un diario le lleva a trabajar a la "mesa", en la hechura del periódico, como secretaria de redacción. Fue cronista de sociales y reportera en diversos medios, editora en el área de difusión y comunicación de la UACJ, desde el año 1995 es articulista en las páginas de opinión de El Diario de Juárez.

${ }^{11}$ El término profesionalización se refiere a la formación y capacitación especializada en ciertas áreas de conocimiento, la certificación de profesiones se ha asignado a las instituciones de educación superior.

${ }^{12}$ En Ciudad Juárez, en 1978 inicia la oferta de licenciatura en Ciencias de la Comunicación, en la Facultad de Ciencias Políticas y Sociales de la Universidad Autónoma de Chihuahua (UACH, 2016), de la que egresan mujeres y hombres que más tarde se convertirían en periodistas. Asimismo, a principios de los 1980 arribaron a esta urbe fronteriza dos egresados y dos egresadas de la escuela de periodismo Carlos Septién García.
} 
El periodismo deja de ser un oficio que se aprendía únicamente de forma empírica. También es un momento de relevo generacional, de manera que, las periodistas enfrentaron tres inconvenientes de aquella época: ser jóvenes, ser mujeres y tener un título universitario.

3) La impronta femenina en el periodismo. Situada esta fase en la década 1990, es un momento en la actividad numerosa y destacada de ellas en los medios, normaliza su participación en áreas del periodismo que antes únicamente se asignaban a hombres.

Aunque continúan siendo pocas las que logran entrar a espacios de fotografía y deportes, su participación se vuelve más común en el reporteo de la información general, incluida las estigmatizadas fuentes policiacas.

Además, en esos años ellas incursionan a puestos de mando intermedio, a jefaturas de información y a coordinaciones de unidades de investigación o de publicaciones especiales, y en el caso de una, a la dirección editorial. ${ }^{13}$

El contexto de ese momento es la gran efervescencia política y participación ciudadana, debido a la alternancia en los gobiernos municipales iniciada en 1983, la movilización ciudadana por la denuncia de fraude electoral en 1986, y la alternancia en la gubernatura en 1992.

En ese tiempo la participación de las mujeres en la información y la crónica política fue destacada. Fue una década en la que ellas marcan su presencia y dejan presente su influencia.

4) La era de las directoras. Entre los años 2010 a 2015 arriban a las direcciones de los principales periódicos juarenses cinco mujeres; tres periodistas a las direcciones editoriales, una en El Diario de Juárez y dos en Norte de Ciudad Juárez, una empresaria a la dirección del periódico Juárez Hoy, y una administradora a la dirección general de Norte de Ciudad Juárez. ${ }^{14}$

El panorama cambió cuando el periódico Norte de Ciudad Juárez cerró, el 2 abril de 2017. Un año antes, también en una estación de radio dedicada al rubro noticioso una mujer fungió como gerente por un lapso de seis meses (Elizabeth Carrillo, en 860 Noticias).

\footnotetext{
${ }^{13}$ Leticia Landavazo Carrillo fue designada directora del diario El Fronterizo en junio de 1991 y de El Mexicano en 1995, ambos periódicos pertenecientes a la Organización Editorial Mexicana, el primero cerró en 1995.

${ }^{14}$ Se trata de las periodistas Rocío Gallegos Rodríguez, Guadalupe Salcido Flores y Miroslava Breach Velducea (asesinada el 23 de marzo de 2017), de la administradora Patricia Quiñones Enriques y de la empresaria Guadalupe Cecilia Lozano Rodríguez.
} 


\section{Derribando muros y techos de cristal}

Desde las subjetividades de las periodistas se realizó un acercamiento que aborda sus procesos vividos y enunciados desde su condición de mujeres en un mundo de trabajo que, hasta hace poco era un territorio de hombres. En las entrevistas cualitativas, ellas, que siempre contaron la historia de otros/as, reconstruyeron y significaron la suya.

Desde la singularidad de cada caso permitieron conocer situaciones que denotan percepciones y mandatos de género aprehendidos por generaciones, a los que cada una enfrentó de diferente modo; algunas de las escenas rememoradas son comunes entre sí, otras fueron experiencias únicas.

En todos los relatos está a la vista la actitud de resistencia de muchos periodistas hacia sus compañeras ${ }^{15}$. Con las practicantes, aspirantes o recién llegadas ellos se escabullían para irse a reportear solos, a su regreso no les explicaban nada o les entregaban los boletines para que redactaran notas de menor importancia.

Como compañeros de reporteras ya contratadas, las ignoraban o las evadían, a pesar de tener instrucciones de realizar trabajos conjuntos, en especial cuando los fotoperiodistas eran asignados a acompañarlas en la cobertura diaria. Describen actitudes de enojo y de vergüenza de ellos, porque "les parecía incómodo ir con una mujer, o que una mujer trabajara como ellos". 16

Con frecuencia me decían que una mujer no tenía por qué andar en esos sitios, alguno sí me llegó a decir que mi lugar era la casa. Eso se volvió más frecuente cuando estaba embarazada. Uno de plano me dijo que él no quería trabajar con una mujer y menos embarazada, que no, que no iría conmigo. ${ }^{17}$

La actitud de negación y/o resistencia a trabajar con mujeres fue un comportamiento generalizado de los periodistas en el momento de las pioneras. Esto fue disminuyendo cuando la presencia femenina en el reporteo y en la mesa de redacción aumentó, pero no desapareció.

\footnotetext{
15 Aunque la actitud de rechazo no se describe como un comportamiento generalizado de todos, sí se señala como una actitud común de muchos compañeros, jefes y subordinados de las periodistas entrevistadas.

${ }^{16}$ Entrevista con experiodista de las iniciadoras en los 1970.

${ }^{17}$ Entrevista con reportera de fuentes policiacas.
} 
Las experiencias de las periodistas y experiodistas muestran varias situaciones sobre esta resistencia de ellos, que deriva en actos de descalificación, desconfianza, menos oportunidades, que pueden configurarse como prácticas discriminatorias.

La resistencia era más común entre los fotoperiodistas, reporteros de deportes y de policiaca, y el cuestionamiento de las capacidades de ellas fue más intenso en el tiempo en que se les asignan fuentes de mayor impacto, durante sus embarazos, y cuando arribaron a los puestos de mando.

En el área de fotografía el ambiente masculino es muy marcado, de manera que a ellas se exponen a ser no sólo descalificadas sino también agredidas; así, dos recuerdan que su trabajo no era reconocido, a una no le creían que fuesen de su autoría las imágenes que entregaba, a otra la acusaban de favoritismo por su relación de pareja con un superior; en otro caso, una fotoperiodista enfrentó tres situaciones de acoso sexual (por parte de su jefe y de dos reporteros), mientras que a Ana ${ }^{18}$ al ser aceptada como fotógrafa de deportes le asignaron un apodo masculino (batillo), así sería "uno de ellos".

Varias periodistas que destacaron por la calidad de su trabajo (son referentes de su época), experimentaron un trato distinto cuando iniciaron su maternidad; compañeros en un caso y jefes en otros, interpretaron que por su condición de madres ellas ya no trabajarían igual, "cuando yo regresé ya embarazada [...] se atrevió a andar diciendo que [...] ya nunca iba a ser la periodista". ${ }^{19}$

Al regreso de su licencia con motivo del embarazo la asignaban a fuentes consideradas como de menor esfuerzo (light) o a trabajo de escritorio; a una le fue negada la oportunidad de participar en un diplomado, y a otra cuando la propusieron para una jefatura el patrón decidió que no; supusieron ellos que como madres ya no trabajarían igual.

La noticia de una próxima maternidad solía ser incómoda o molesta para los superiores de ellas, a tal grado que, en un periódico incluían la prueba de embarazo antes de

\footnotetext{
${ }^{18}$ Seudónimo que usamos por el compromiso de confidencialidad establecido cuando ella aceptó la entrevista.

${ }^{19}$ Entrevista con periodista y escritora, reportera en las décadas de 1980 y 1990.
} 
asignarles planta, y en otro durante un examen médico previo al contrato, incluían preguntas de su vida sexual.

Una estrategia distinta ante la maternidad, por parte de un director, fue la de violar los derechos de dos periodistas, con el consentimiento de ellas; les solicitó no suspender sus tareas (como editoras y jefas) aunque tuviesen la incapacidad laboral, es decir, que trabajaran hasta que fuese el momento del parto y regresaran a la brevedad posible.

Esta situación evocada por una como prueba de lealtad al medio del que luego fue despedida, y por otra como una situación forzada por las condiciones del periódico, apunta a que ellas se sintieron reconocidas como necesarias en actividades cruciales para la edición diaria del medio, pero desde otra perspectiva, se aprecia no únicamente la violación de un derecho sino también la instrumentalización del sentido de compromiso que manifiestan las mujeres en las empresas periodísticas.

Cabe aclarar que, aunque la mayoría de las entrevistadas son mujeres que todavía laboran en los medios o en otras organizaciones, también se documentaron casos en los que, debido a la demanda del cumplimiento de los roles esperados y asumidos por ellas (la maternidad y la administración del hogar), renunciaron a este empleo, o tuvieron prolongadas pausas.

Adicionalmente, una cuestión más para analizar son las representaciones que las periodistas hacen sobre su relación con los hombres en el trabajo. Desde distintos referentes abordan el tema; pocas tienen una visión clara de que se enfrentan a un sistema patriarcal, aunque relatan experiencias en las que se percataron de que son ellos quienes no saben relacionarse con mujeres como compañeras, como iguales, y menos como sus superioras.

Algunas perciben como natural o lógica la resistencia de los varones ante la presencia y el ascenso de las mujeres, pero cuidan no asumir una postura desde su género que se interprete como feminismo; se detectaron prejuicios y escaso conocimiento del feminismo en varias entrevistadas, que en sus expresiones relacionan esta ideología como una posición "radical", o como una que "victimiza" a las mujeres.

Además, varias de las periodistas entrevistadas reflexionan el tema desde sus experiencias previas con el sexo opuesto, y atribuyen su exitosa incursión en este mundo al hecho de proceder de una familia de varones. 
Dos mujeres de distintas generaciones (20 años de distancia en su inicio en el periodismo), manifestaron que se les facilitó trabajar en un espacio más masculino que femenino, debido a sus antecedentes familiares; en sus esferas privadas predominaba la presencia de ellos, hermanos y primos, por lo cual sabían cómo relacionarse con ellos.

Sugerente es -siguiendo estas dos conversaciones-, que una se retrate como no femenina con ellos ("nada modosita, más bien llevadita") ${ }^{20}$ y otra (que ha ocupado dos puestos de mando) señale que le resulta mejor trabajar con los hombres que con las mujeres, porque "suelen ser más complicadas", ${ }^{21}$ rasgo que enuncia para ellas, pero del que se deslinda al no incluirse en un "somos".

El análisis de las conversaciones entabladas en las entrevistas y el grupo focal con mujeres periodistas y experiodistas, arroja que, sus experiencias están marcadas con tropiezos y caídas ante los obstáculos que afrontaron por su condición sexual, laberintos y techos de cristal.

Pero, también hubo discursos en las que se responsabilizan de esta situación, al indicar que si había trato desigual, en los salarios - por ejemplo-era porque ellas lo permitían, porque no se quejaban.

Asimismo, surgieron las manifestaciones de satisfacción y orgullo cuando ellas evocaron sus atrevimientos y logros al desafiar una esfera en la que ser mujer no sólo era novedoso, sino desafiante por las lógicas inmanentes a un sistema de géneros que desfavorece a las mujeres.

Cabe señalar que el tema de las propuestas o insinuaciones de carácter sexual hacia ellas, por parte de jefes, compañeros o informantes, surge en varias de las entrevistas. En el caso de una comunicadora derivó en acosos que nunca denunció.

Estas cuestiones fueron remembradas como experiencias que en su momento sí les generaron preocupaciones, pero distintas al temer por su integridad; aprendieron a evadir y

\footnotetext{
${ }^{20}$ Entrevista con ex periodista, reportera, conductora y columnista política.

${ }^{21}$ Entrevista con periodista, exdirectora editorial.
} 
callar las propuestas y el acoso para lograr acceso a la información, para no perder el empleo, e incluso para evitar conflictos con sus parejas.

En relación con la situación salarial, las periodistas colocaron este tema en la conversación desarrollada en el grupo focal.

Mencionaron averiguaciones informales que hicieron en los medios donde laboraban, acerca de los sueldos de sus compañeros, y sí, en algunos casos encontraron diferencias que motivaron reclamos, e incluso una renuncia.

También discutieron el asunto de la inestabilidad en el empleo; quienes iniciaron como practicantes esperaron mayor tiempo que sus compañeros varones para ser contratadas.

En el caso de quienes incursionaron en el periodismo radiofónico, los obstáculos que enfrentaron se manifestaron además de reducidos salarios, en los horarios que les asignaban (nocturnos, los de menor audiencia), y presiones para que no aceptaran incapacidades médicas porque serían despedidas.

El tema de la salud es un asunto escabroso para ellas, pues es uno de los principales inconvenientes asociados a su sexo que les endilgaban para descalificarlas, para predecir que no podrían desempeñarse igual que sus compañeros hombres.

Por ello, en sus labores evitaban mostrar algún padecimiento, tampoco ausentarse o incapacitarse cuando tenían afecciones relacionadas a su sexo, o "enfermedades de mujer", tal como lo expresaron en las entrevistas.

Laura, hoy desempleada describe que: “Ahí [en la radio] eran más misóginos que en los periódicos, y cuando comencé a tener problemas de salud me negaban permisos, se enojaban si llevaba incapacidades, me insinuaban que podrían despedirme.

Ahora pienso que dejé pasar muchas cuestiones de salud que a la larga me afectaron. Finalmente renuncié, por las presiones y para tener tiempo para mis hijos,". ${ }^{22}$

En el mismo medio donde estaba Laura, 20 años después estuvo a cargo de la gerencia una mujer, que expuso los recelos de los directivos varones hacia el ascenso de las mujeres, como un temor a lo desconocido, a competir con quién no conocen, con quienes no saben relacionarse.

\footnotetext{
${ }^{22}$ Entrevista con reportera de información general y columnista, identificada aquí con el seudónimo Laura
} 
En las entrevistas con quienes ocupan u ocuparon puestos de mando, abundaron las descripciones de un clima hostil. Fueron recibidas con discrepancias acerca de sus facultades de decisión, con prácticas de boicot, desconfianza, descalificaciones y, en algunos casos, abiertas confrontaciones.

Para ilustrar lo anterior, enseguida se presentan fragmentos de las conversaciones con tres de las directivas en cuestión.

Si sentí (el rechazo), no de subordinados, sino de los compañeros [...] Tomó un tiempo que entendieran que cuando yo daba instrucciones ya eran decisiones para acatarse [...] seguían esperando que las consultara, me preguntaban que si ya lo aprobó [...] se sentían con atribuciones para rebatir todas mis decisiones. ${ }^{23}$

He sentido, al principio sentía el menosprecio [...] no al trabajo, sino a mi persona [...] en las reuniones de los dueños de medios o de directores y como que era la única mujer $[\ldots]$ me querían a fuerzas poner como la esposa de $[\ldots]$ no querían darme voz propia. ${ }^{24}$

Descalifican tu trabajo, no quieren colaborar [...] y en parte de hacer como demasiado ruido y mucha descalificación, como tratando de tumbarte, de no darte la oportunidad de que pudieras ir creciendo [...] eran situaciones así, bastante [...] desagradables, fuertes. ${ }^{25}$

Entonces esa era la actitud de él, o sea "esta [...] que me va a venir a mí a decir qué hacer". [...] él, abiertamente [...] por ejemplo, le digo "oye va a andar el fiscal en X lugar, ve por favor" y él responde "no, ¿para qué? ¿Y qué quieres que le pregunte?”... y claro que todos, [...] todos alrededor. Nos rodeaban para ver qué me contestaba y a ver quién podía más [...] Yo decía: "por qué, yo no le hago nada, yo no lo maltrato". ${ }^{26}$

El tema de las implicaciones de la participación de mujeres en el periodismo también se abordó en las entrevistas.

Sobre la incorporación de sus perspectivas a la producción noticiosa hay dos percepciones; una en el sentido de que no hay diferencias substanciales entre el abordaje que hacen los periodistas y el que realizan ellas; la otra es que por la sensibilidad que se atribuye a las mujeres, les asignan ciertos temas o asuntos, con lo que se excluye o discrimina a los

\footnotetext{
${ }^{23}$ Entrevista con directora editorial.

${ }^{24}$ Entrevista con empresaria y directora general.

${ }^{25}$ Entrevista con directora editorial.

${ }^{26}$ Entrevista con jefa de información.
} 
hombres, porque a la empresa le interesa explotar este atributo. En este mismo sentido, mencionan que con frecuencia les exigen más trabajo a ellas.

A veces es porque como que necesitan alguien que sepa hablar de otra manera, que se acerque con cuidado a los familiares [...] pero también, este, muchas veces porque nos consideran más responsables, cumplidas.

Esto no siempre es bueno, saben que nos vamos a quedar, que no les dejamos tirado el trabajo, y si, a lo mejor te hace ser más destacada, más notas de primera, pero también te hacen trabajar más. Es bien curioso, ¿no?, antes no nos querían en ciertas fuentes, que porque, si éramos mamás, o porque te casaste, creían que querríamos irnos tempranito, que les dejaríamos malhechas las notas, y ahora parece al revés. ${ }^{27}$

\section{Avances del análisis de contenido}

Como se señaló antes, el análisis de contenido se aplicó para evaluar en cuáles espacios es mayor la actividad de las periodistas, y si su participación en las decisiones editoriales se relaciona con las representaciones del género femenino, es decir, el tratamiento mediático a las mujeres.

Los avances de este análisis se orientan a considerar que el cambio de género en el mando editorial de los medios no conduce a cambios significativos de las representaciones de las mujeres en las noticias. Esto se puede comprender con el conocimiento de que los medios son estructuras del sistema de géneros basado en el sexo, que prioriza la perspectiva y el poder masculino.

En esa lógica, los periódicos dirigidos por mujeres continúan con la política editorial y comercial de difusión de contenidos que reafirman roles de género y, además, en los que nos subrepresentan a las mujeres como fuentes autorizadas o expertas, o como protagonistas de la información. ${ }^{28}$

\footnotetext{
${ }^{27}$ Entrevista con reportera.

${ }^{28}$ Como se ha documentado en varios estudios de especialistas en comunicación y género (Vega, 2009, Vega y Hernández, 2009), los medios contribuyen de forma notable a la reproducción del sistema patriarcal, cotidianamente difunden "estereotipos sexistas que, o asocian a las mujeres a roles tradicionales (madres, esposas y amas de casa) en donde se enfatiza su supuesta fragilidad y vulnerabilidad y su adscripción social al espacio doméstico, o que las representan como objetos sexuales" (Vega, 2009, sp).
} 


\section{¿Dónde publican ellas?}

En la revisión de las firmas o créditos de contenidos, para observar la paridad entre autores y autoras, se encontró que en una cantidad mayor al cincuenta por ciento de noticias no se publica la autoría de alguna persona, ${ }^{29}$ lo cual deriva de dos situaciones: que en los contenidos firmados por agencias informativas (que nutren muchas secciones) pocas veces personalizan el crédito, y que, por razones de seguridad, desde el año 2010 en ciertas informaciones de cobertura local en los periódicos juarenses se publica como firma la palabra “staff” o la frase "de la redacción".

No obstante, queda para la reflexión que entre los contenidos con autoría personalizada sea mayor la cantidad de noticias escritas por hombres. Otro dato importante es que los porcentajes de la paridad obtenidos de esta revisión (56 por ciento de notas firmadas por hombres y 44 por ciento por mujeres), coincidan en ambos periódicos. ${ }^{30}$

En el caso de El Diario de Juárez, de los 340 contenidos firmados, 151 (44 por ciento) corresponden a notas suscritas por mujeres, ante 189 (56 por ciento) de hombres. Al desagregar los datos para comparar el antes y después de que la dirección editorial la ocupara una mujer, en El Diario de Juárez se encontró que, en los de años anteriores a la directora, de 393 contenidos 151 tienen firma personalizada, de los cuales 71 son de mujeres y 80 de hombres, la relación es 47 ante 53 por ciento.

Por otra parte, en los contenidos publicados durante el mando editorial femenino, de los 189 que tienen firma, 80 (42 por ciento) los suscriben mujeres y 109 (58 por ciento) hombres.

Como se observa, en ese medio la diferencia sugiere ser más amplia en el período de la directora.

No obstante, estos ejemplares son del periodo posterior a la aguda crisis de violencia que vivió Ciudad Juárez, por lo que se tendría una consideración para interpretar esos datos, esta es la política editorial de no firmar ciertas noticias, ya que en este matutino son dos mujeres quienes cubren (desde 2010) las fuentes informativas de seguridad y justicia

\footnotetext{
${ }^{29}$ En la muestra de El Diario de Juárez, de los 799, 459 (57\%) no tienen firma personalizada. En los ejemplares revisados de Norte de Ciudad Juárez, de 731 en 459 (63\%) no identifican a un autor o autora.

${ }^{30}$ Se trata de diarios matutinos muy distintos, en cantidad de páginas, en formatos, y en impacto de distribución. El Diario de Juárez tenía mayor circulación y publicidad que Norte de Ciudad Juárez, éste dejó de operar el 3 de abril de 2017, después de 27 años.
} 
(corporaciones policiacas, penales y juzgados), en las cuales se genera información que en muchos casos se identifica como producción de "staff".

En este sentido, la revisión de estos registros, la conclusión de que las diferencias, entre el antes y después de la jefatura femenina, signifique que hay una menor participación de mujeres periodistas, cuando el medio lo dirige una mujer.

Asimismo, al desagregar los contenidos suscritos por hombres y mujeres en cada una de las secciones de los ejemplares, lo que se encontró en los ejemplares de El Diario de Juárez es que, en los espacios de información general la relación de contenidos firmados por mujeres y hombres casi se distribuye a la par: la diferencia es del tres por ciento más de las firmas de ellas.

Además, en las informaciones consideradas de mayor impacto, las seleccionadas para la portada o primera plana del periódico, también destacan las mujeres con 13 contenidos ante cinco suscritos por hombres.

En contraste, los contenidos de la sección de opinión indican que la participación de mujeres en esos espacios es mínima, de 28 artículos solamente tres son de mujeres.

Otro dato significativo es que en la sección de deportes ninguna mujer participa como autora. Del mismo modo, es relevante que, en secciones de entretenimiento, en otros tiempos consideradas "femeninas", se encontraron más autores que autoras.

En lo que se refiere al periódico Norte de Ciudad Juárez, la diferencia encontrada sugiere que son más los hombres quienes participan en la producción noticiosa y artículos de opinión; de un total de 340 contenidos con firma personalizada, 189 (56 por ciento) son firmados por hombres y 151 (44 por ciento) por mujeres.

Al focalizar la autoría de contenidos por sección, esta revisión arrojó que, en el espacio de información general, de 229 contenidos firmados, en 94 (41 por ciento) sus autoras son mujeres y en 135 (59 por ciento) hombres.

Al ser revisados estos mensajes en los subconjuntos del antes y después del nombramiento de la directora editorial, los hallazgos permiten inferir que la participación femenina no aumentó; en el primer periodo la relación entre notas suscritas por mujeres y hombres fue de 39 (34 por ciento) de autoría femenina ante 74 (66 por ciento) de autores 
varones, y en el segundo fueron 55 firmas de mujeres ante 63 de hombres, un 47 ante un 53 por ciento.

En el caso de la primera plana o portada, en el periodo previo a la dirección de una mujer, de ocho contenidos solamente uno es de una mujer, siete son suscritos por hombres; en los ejemplares de los años posteriores a la directora, la diferencia se sostiene en el mismo orden: sólo tres notas de primera plana son suscritas por mujeres y diez por varones.

La revisión de las portadas arroja datos que ilustran si hay o no diferencias en la asignación de temas y fuentes para hombres y mujeres, ya que en ambos medios siempre se incluyen contenidos locales.

Y precisamente es en las primeras planas de los ejemplares revisados, en donde se encontraron diferencias significativas entre ambos periódicos; en El Diario de Juárez la mayor parte de los contenidos son de ellas (13 ante 5) relación que se invierte en el periódico Norte de Ciudad Juárez (4 ante 17).

En el tiempo que se realizó el trabajo empírico de esta investigación (septiembre 2016-abril 2017) se constató que, en información general, en El Diario laboraban más mujeres reporteras (siete) que en Norte (tres).

Otro dato significativo es que, en las páginas de opinión y de deportes en ambos medios es notable la ausencia de voces femeninas. Sólo en El Diario de Juárez se identificó a articulistas mujeres (tres).

\section{Representaciones: víctimas o festejadas.}

Para analizar cómo se representa a las mujeres en los contenidos de ambos periódicos primeramente se seleccionaron los mensajes en que son mencionadas, así sea como protagonistas, como tema o como informantes.

Los datos cuantitativos de esta revisión permiten deducir que, en lo general es poca la representatividad de las mujeres en las noticias, independientemente del rol en que se les coloque. 
En el caso de El Diario de Juárez les mensajes que involucran a mujeres son 203, que representan el 25.40 por ciento de los 799 contenidos en los seis ejemplares; en tanto que de las 731 publicaciones revisadas en siete ejemplares de Norte de Ciudad Juárez, solamente 148 (20 por ciento) implican a mujeres.

Asimismo, cuando tales resultados se separan en los años anteriores y posteriores a las directoras, se observa que no hay cambio significativo sobre las menciones de mujeres en información general.

Al momento de elaborar este documento de avances se analizaban los contenidos para conocer a mayor detalle cómo se representa a las mujeres en las noticias. Para esto se utilizaron cuatro rubros: protagonistas, participantes, tema y fuente de información.

En los casos en que las mujeres son mencionadas como protagonistas o como tema de los mensajes, se aplicó una segunda clasificación para indicar si fueron descritas como empoderadas, como víctimas o como culpables.

Asimismo, si se les refiere como fuente de información, se revisó si fueron abordadas como funcionarias, voceras, especialistas o como vox populli (una voz entre muchas, en los sondeos)

Con los datos preliminares de dicho análisis, se encuentra como tendencia que el tratamiento que se dio a las mujeres en los contenidos de información general en ambos diarios coloca a las mujeres como protagonistas de los mensajes, y que este protagonismo se inscribe principalmente en dos circunstancias: como víctimas y como festejadas, y en pocos casos como empoderadas en las secciones de espectáculos y de deportes.

Las informaciones que las señalan como víctimas, se trata de mensajes de los espacios de información general y local, destacan las menciones de los casos de violencia contra mujeres.

Los mensajes que las abordan como festejadas son noticias de las páginas de sociales, que dan cuenta de eventos como bodas, quinceañeras y graduaciones, entre otros.

Una consideración contextual para el análisis de estos datos es que en el aspecto de las víctimas de violencia en Ciudad Juárez hay dos temas que destacan porque su incidencia se ha visibilizado, estos son: los feminicidios y las desapariciones de mujeres. 


\section{PALABRAS FINALES}

Los cuatro momentos sociohistóricos de la participación de las mujeres periodistas en las áreas de información general y opinión informan de cambios graduales que conciernen a los avances de la presencia de las mujeres en el mundo del trabajo, campo de la esfera pública.

Las experiencias de las pioneras -empíricas casi todas-, de quienes al conquistar un espacio abrieron las puertas para otras, fueron preámbulo de una irrupción femenina que rompió techos y muros de cristal erigidos sutilmente desde la lógica masculina dominante en el ámbito periodístico.

Desde sus subjetividades, las participantes en este proyecto reflexionaron en voz alta sus experiencias. Se trata de mujeres que decidieron ser periodistas, que en ocasiones esquivaron o minimizaron situaciones de descalificación por su condición de género.

En otro momento fueron reconocidas y utilizadas bajo la exigencia de un rendimiento superior al de ellos, por atributos supuestamente femeninos (responsabilidad, compromiso, sensibilidad).

Algunas entrevistadas recodaron el acoso sexual no denunciado, otras el rechazo abierto a su presencia, y también la exigencia de su masculinización.

Finalmente, los hallazgos preliminares del análisis de contenido nos permiten apreciar que, permanece un factor frecuentemente señalado como sostén de la cultura androcentrista, este es el tratamiento de los medios hacia las mujeres, el cual parece no haberse modificado de forma significativa durante las direcciones editoriales femeninas.

Sin embargo, las consecuencias editoriales de la participación de ellas en los puestos de decisión pudieran tener otro tipo de consecuencias no exploradas en este proyecto. 


\section{REFERENCIAS}

Barberá, E., Ramos, A. y Candela, C. (2011). "Laberinto de cristal en el liderazgo de las mujeres", Psicothema Vol. 23 No. 2 pp. 173-179. Recuperado de http://www.psicothema.com/pdf/3867.pdf

Carreño, J. (2000). "Cien años de subordinación. Un modelo histórico de la relación entre prensa y poder en el Siglo XX", Sala de Prensa, No. 16. Año III. Vol.2. Recuperado de http://www.saladeprensa.org/art102.htm

Castillo, L. (2011). "Las mujeres en el periodismo chihuahuense”, en Payán, Luis, Bass, Sonia, Pérez, Martha y Rodríguez, Jesús. (coords.) De soldaderas a activistas. La mujer chihuahuense en los albores del siglo XXI. México, Ed. Eón, pp.135-156

CIMAC (2011). Hacia la construcción de un periodismo no sexista (2a. Ed.) Recuperado de http://www.cimac.org.mx/cedoc/publicaciones_cimac/hacia_la_construccion.pdf

Denzin, N. \& Lincoln, Y. (2011). Handbook of Qualitative Research. London: Sage

Fernández, M. (2011). "Mujeres periodistas: Cambio social y democratización de los medios en México", Revista Mexicana de Comunicación. Recuperado de http://mexicanadecomunicacion.com.mx/rmc/2011/08/10/mujeres-periodistas-cambiosocial-y-democratizacion-de-los-medios-en-mexico

García, C. (2012). Las mujeres en la historia de la prensa. Una mirada a cinco siglos de participación femenina en México, México: Documentación y Estudios de las Mujeres A.C.

GMMP, WACC, CIMAC e ITESO (2015) Proyecto de Monitoreo Global de Medios 2015. México. Informe Nacional. Recuperado de http://cdn.agilitycms.com/who-makes-thenews/Imported/reports_2015/national/Mexico.pdf

Hernández E. (2009). "La construcción de la realidad social a través de la mediación femenina, un repaso histórico" en Romero, M. (coord.), Espejismos mediáticos. Ensayos sobre la construcción de la realidad periodística. México: EDIMPRO S.A. de C.V.

Hernández, M. Elena (2010). Franquicias periodísticas y sinergias productivas en la prensa mexicana: en busca de nuevos modelos de financiamiento en Estudios sobre periodismo. Marcos de interpretación para el contexto mexicano 2010. México: Editorial CUCSH-UDG, pp. 55-121

Rosado, M. J. (2016). "La función directiva desde una perspectiva de género", XIV Edición Premios Emprendedores \& Empleo. Madrid: Unidad Editorial Información Económica e Instituto de Empresa S.L / IMPRIMEX. S.A. Recuperado de http://isdfundacion.org/wpcontent/uploads/2016/12/La-funci\%C3\%B3n-directiva-desde-una-perspectiva-deg\%C3\%A9nero.pdf

Strauss, A. y Corbin, J. (2002) Bases de la investigación cualitativa. Técnicas y procedimientos para desarrollar la teoría fundamentada (Zimmerman Eva, trad.) Colombia: Universidad de Antioquía 
UACH (2016). Historia de la FCPyS. Recuperado de http://fcpys.uach.mx/administracion_20102016/historia_fcpys/

UNESCO (2011) Informe Mundial sobre la Condición de la Mujer en los Medios de Comunicación. Recuperado de http://www.unesco.org/new/es/communication-andinformation/crosscutting-priorities/gender-and-media/women-make-the-news/facts-andfigures/

Valles, R. M. (2006). "Mujeres periodistas: empoderamiento restringido", mayo-agosto 2006, Recuperado de http://www.redalyc.org/articulo.oa?id=42119711

Vega, A. y Hernández, J., "Género y Comunicación: las claves de una agenda política y académica de investigación" (2009) en Vega, A. (coord.), La Comunicación en México, Una agenda de Investigación, México: CEIICH UNAM, PPCPYS UNAM, AMIC, UABC, UJAT, pp. 213 243

Vega, A., (2007) "Género y Comunicación. Las Claves de una Agenda Académica, Política y Personal de Investigación" [ponencia] 50 Conferencia Internacional, Asociación Internacional de Investigación en Medios y Comunicación (IAMCR), París, julio 2007. Recuperado de http://www.mujeresnet.info/2008/06/gnero-y-comunicacin-las-claves-deuna.html

Vega, A., (2012) El derecho de las mujeres a comunicar. Claves del acceso y participación de las mujeres en las industrias de comunicación en Orozco, G. (coord.) TVMorfosis. La televisión abierta hacia la sociedad de redes. México: Productora de contenidos culturales Sagon Repoll 